\title{
TREATMENT OUTCOMES OF EXTRACORPOREAL SHOCK WAVE LITHOTRIPSY FOR URINARY CALCULI
}

\section{Dr Nirmal K P* \\ Dr Manoj Kumar G}

\section{Dr Sunil R}

\section{Dr. Aravind S \\ Ganapath}

ABSTRACT

ESWL is considered as a standard treatment for renal calculi less than $20 \mathrm{mms}$, but the outcome of this therapy depends on different factors including stone composition, stone location, pelvicalyceal anatomy and stone size. This study was conducted to assess the treatment outcomes of patients undergoing ESWL for renal calculi and the factors influencing it. This was a descriptive study conducted in the Department of Urology, Government Medical College,Thiruvananthapuram. The study period was one year and 150 patients were enrolled. Overall success rate of ESWL in our study was $76.7 \%$. Regarding the treatment outcomes our study concluded that the overall success rate of ESWL is $76.7 \%$. But factors like lower calyceal location, skin to stone distance $>10 \mathrm{~cm}$, density $>950 \mathrm{HU}$ and size $>1.5 \mathrm{cms}$ are associated with failure of fragmentation by ESWL.

\section{KEYWORDS : Urolithiasis, Lithotripsy, ESWL}

INTRODUCTION

Urolithiasis is a disease known since ages. Stones maybe formed anywhere in the genito urinary tract. It mainly affects men but the incidence in females is on the rise(1). Extracorporeal Shock Wave Lithotripsy (ESWL) is used for most of the renal stones especially those with size range of 10 $20 \mathrm{~mm}^{1}$. The success rate of this treatment modality is in the range of $60-90 \%$ in various series ${ }^{1-3}$. The main advantage of ESWL is that it offers the least invasive treatment. The outcome of ESWL treatment depends on many factors including stone site, size, composition and the presence of obstruction or infection $^{4,5}$. Preoperative urinary tract imaging is required in all patients before any surgical intervention, to assess stone size, location, characteristics, and anatomical abnormality. Non Contrast Computerized Tomography( NCCT) is used as the imaging modality of choice for urinary stones. In previous studies the NCCT attenuation value of urinary calculi has been investigated as a method to predict the outcome of ESWL ${ }^{6}$. NCCT visualizes almost all renal stone and has sensitivities and specificities of greater than $95 \%$, which is considerably better than any other imaging modality, even at low dose protocols and across all body habitus. In addition, NCCT has the advantage of demonstrating three dimensional anatomic information about the kidney and adjacent organs, relevant treatment strategy considerations such as skin-tostone distance, and stone density characteristics to guide the treatment choices.

\section{Aim of the study}

To estimate the treatment outcomes and factors influencing it among patients with renal calculi undergoing ESWL in Department of Urology, Government Medical College, Thiruvananthapuram.

\section{Methodology}

Study Design: Descriptive study.

Study Setting: Department of Urology, Government Medical College, Thiruvananthapuram.

Study Population: Patients presenting with Renal calculi to Urology OPD at $\mathrm{MCH}$, Thiruvananthapuram for a period of $\mathrm{l}$ year extending from April 2017-March 2018.
Study Subjects: Patients presenting to Urology OPD at $\mathrm{MCH}$ Thiruvananthapuram with Renal calculi of size $5 \mathrm{~mm}$ to $20 \mathrm{~mm}$ and are willing for ESWL.

\section{Exclusion Criteria}

1. Patients who are not willing to give consent for the study.

2. Patients of age less than 18 years

3. Patients with abnormal renal function

4. Patients with major renal abnormalities

5. Patients with urinary tract infection

StudyPeriod: For a period of 1 year extending from lst April 2017 to 31 st March 2018.

Sampling: Consecutive sampling

Sample size: $\mathrm{N}=4 \mathrm{PQ} / \mathrm{d}^{2}, \mathrm{P}=40 \%, \mathrm{Q}=60 \%, \mathrm{~d}=20 \%$ relative precision; $d=8$

$\mathrm{N}=150$

Study Variables

1. Stone size

2. Stone location

3. Stone density (as measured by Hounsfield Units [HU]) by NCCT

4. Skin to stone distance (SSD) measured by NCCT

Outcome-success - $<5 \mathrm{~mm}$ residual fragment after 6 weeks.

Data analysis

1. Data entered in Excel sheet

2. SPSS software used for analysis of data

\section{RESULTS}

Total 150 patients were recruited for the study. Majority of the patients $(79.4 \%)$ were of $30-60$ years age group. Of the 150 patients, 113 were males ( $75.3 \%$ ) with mean age of 45 years. Urinary stone sizes ranged between $7 \mathrm{~mm}-20 \mathrm{~mm} \mathrm{mms}$ of which 56(37.3\%) were located in the lower calyx, 44(29.3\%) in the pelvis and rest 50 (33.4\%) were located in other sites (i.e.13 in upper calyx $(8.7 \%), 24$ in middle calyx $(16 \%), 13$ in upper ureter $(8.7 \%)$. In 81 (54\%) patients stones were located on the right side. The skin to stone distance was $<10 \mathrm{~cm}$ in $76(50.7 \%)$ cases. The success rate of ESWL was $115(76.7 \%)$. Success rate according to stone location was least in the lower pole stones 
and maximum in the upper calyx and upper ureter stones (Table 1). Other factors contributing to successful ESWL in our study were low skin to stone distance and low stone density. Skin stone distance $<10 \mathrm{~cm}$ and stone density $<920 \mathrm{HU}$ has the maximum success rate (Table 2 ).

Table 1-Site wise distribution of success of ESWL

\begin{tabular}{|c|c|c|c|c|}
\hline Site & $\mathbf{N}$ & \% of reduction in size ater 6 weeks & \multirow{2}{*}{$\mathbf{p}$} \\
\cline { 3 - 4 } & & Mean & sd & \\
\hline Upper & 13 & 88.0 & 12.6 & \multirow{2}{*}{$<0.001$} \\
\hline Middle & 24 & 74.0 & 33.9 & \\
\hline Lower & 56 & 51.1 & 38.7 & \\
\hline Upper ureter & 13 & 78.7 & 18.2 & \\
\hline Pelvis & 44 & 74.0 & 27.1 & \\
\hline
\end{tabular}

Table 2- Distribution of success of ESWL based on skin to stone distance

\begin{tabular}{|c|c|c|c|c|}
\hline Distance & $\mathbf{N}$ & \% of reduction in size ater 6 weeks & \multirow{2}{*}{$\mathbf{p}$} \\
\cline { 3 - 4 } & & Mean & sd & \\
\hline$<10 \mathrm{~cm}$ & 76 & 80.1 & 25.4 & $<0.001$ \\
\hline$>10 \mathrm{~cm}$ & 74 & 53.7 & 36.4 & \\
\hline
\end{tabular}

\section{DISCUSSION}

ESWL is considered as a standard treatment for renal calculi less than $20 \mathrm{mms}$, but the outcome of this therapy depends on different factors including stone composition, stone location, pelvicalyceal anatomy and stone size. Our study showed calculi less than $15 \mathrm{~mm}$ are best suitable for ESWL.

Joseph et $\mathrm{al}^{2}$ suggested that stones with $\mathrm{CT}$ attenuation value of greater than 950 Hounsfield units and 7500 shockwaves failed to achieve fragmentation. Similar to Joseph et al, the results of this study clearly reveals that stones with densities exceeding 950 Hounsfield units are difficult to fragment.

Gupta et $\mathrm{al}^{6}$ showed that the worst outcome of ESWL was in patients with calculus densities of more than 750 Hounsfield units and diameters of more than $11 \mathrm{~mm}$, and their clearance rate was only $60 \%$. However, contrary to Gupta et al, this study revealed that stone diameters of up to $15 \mathrm{mms}$ may still (depending on stone density) respond successfully to ESWL treatment. Even though the results of this study have identified both stone density and size as significant contributors to ESWL treatment success rate, it also revealed that stone density is the determinant factor of treatment success for stone sizes of $15 \mathrm{mms}$ or smaller.

In our study, the success of ESWL treatment is almost always guaranteed when the CT attenuation value is less than 920 Hounsfield units, while, at the same time, treatment failure is almost certain when the CT attenuation value exceeds 1343.5 HU. Stone densities in the range of 920-1343.5HU may, or may not, respond successfully to ESWL treatment.

To date, few clinical studies have compared the stone density with the outcome of ESWL in vivo. In a study of 30 patients, Joseph et al found that patients with calculi of less than 500 Hounsfield units had complete clearance and required a median of 2500 shockwaves, patients with calculi of 500-1000 Hounsfield units had a clearance rate of $86 \%$ and required a median of 3390 shockwaves, and patients with calculi of more than 1000 Hounsfield units had a clearance rate of $55 \%$ only and required a median of 7300 shockwaves. Study by Joseph et al based on 65 patients, showed that stones with densities less than 500 Hounsfield units have $94 \%$ clearance rate and required a median of 2800 shockwaves, patients with stone densities of $500-1000$ Hounsfield units have $76 \%$ clearance rate and required a median of 3700 shockwaves, and patients with stone densities more than 1000 Hounsfield units have $42 \%$ clearance rate and required a median of 7800 shockwaves.

Pareek et $\mathrm{al}^{7}$ correlated calculus density with stone clearance in their study of 100 patients. They concluded that patients with residual calculi had a mean calculus density of more than 900 Hounsfield units. However, they did not correlated the calculus density with fragmentation. The results of this study concurs with Pareek et al's results in that stone clearance is unlikely when stone density exceeds 1000 Hounsfield units. The results of this study supports those of Joseph et al in that CT stone density has a positive correlation with the number of shockwaves needed for fragmentation. Also, the results of this study concurs with the results of previous studies, that stone location has a significant effect on fragmentation success and clearance with lower calyceal stones have less success rates compared to other locations.

In conclusion, ESWL treatment outcome is strongly, but inversely, dependent on stone density. Stones with CT densities of 950 Hounsfield units or less undergo successful treatment requiring lesser number of shock waves and sessions. Large stones more than $1.5 \mathrm{~cm}$ and lower calyceal location are resistant to ESWL.

\section{CONCLUSION}

This study concludes that the overall success rate of ESWL is $76.7 \%$. But factors like lower calyceal location, skin to stone distance $>10 \mathrm{~cm}$, density $>950 \mathrm{HU}$ and size $>1.5 \mathrm{cms}$ are associated with failure of fragmentation by ESWL. So with proper patient selection the outcome of ESWL can be increased.

\section{REFERENCES}

1. Cass AS. Comparison of first generation (Dornier HM3) and second generation (Medstone STS) lithotriptors: treatment results with 13,864 renal and ureteric calculi. J Urol 1995;153:588.

2. Joseph P. Mandal AK, Sharma SK. CT attenuation value of renal calculus: can it predict successful fragmentation of the calculus by extracorporeal shockwave lithotripsy? A preliminary study. J Urol 2002;167:1968.

3. Lingeman JE, Newman D, Mertz JH, et al. Extracorporeal shockwave lithotripsy: the Methodist Indiana experience. J Urol 1996; 135:1134

4. Martin TV, Sosa RE. Shockwave lithotripsy. In Walsh PC, Retick AB, Vaughan ED Jr, Wein AJ, eds, Campbeils urology. Philadelphia: WB Saunders Inc 1998:2735-52

5. Bon D, Dore B, Irani J, et al. Radiographic prognostic criteria for extracorporeal shock-wave lithotripsy. Urology 1996;48:556.

6. Dretler SP, Polykoff G. Calcium oxalate stone morphology: fine tuning our therapeutic distinctions. J Urol 1996; 155:828-33.

7. Herremans D. Vandeursen H, Pittomvills G, et al. In vitro analysis of urinary calculi: type differentiation using computed tomography and bone densitometry. Br J Urol 1993;72:544-8. 